Oral Section

\title{
Cellular and transcriptional responses of SH-SY5Y human neurocytes following in vitro exposure to Gelsemium sempervirens
}

\author{
Paolo Bellavite ${ }^{1}$, Marta Marzotto ${ }^{1}$, Debora Olioso ${ }^{1}$, Mirko Cristofoletti ${ }^{1}$, \\ Maurizio Brizzi ${ }^{2}$, Paola Tononi ${ }^{3}$, Ilaria Pierpaola Dal Prà ${ }^{4}$, Ubaldo Armato ${ }^{4}$ \\ ${ }^{1}$ Department of Pathology and Diagnostics, University of Verona, Verona, Italy \\ 2 Department of Statistical Sciences, University of Bologna, Bologna, Italy \\ ${ }^{3}$ Department of Biotechnology, University of Verona, Verona, Italy \\ ${ }^{4}$ Department of Life and Reproduction Sciences, University of Verona, Verona, Italy
}

\begin{abstract}
Background: Gelsemium sempervirens (Gelsemium s.) is a highly toxic plant but is employed at low doses and/or high dilutions as an anxiolytic and antidepressant. Previous investigations in our laboratory [1,2] have shown a significant anxiolytic-like activity of Gelsemium s., using emotional response models in laboratory mice. Although there is some biochemical evidence of a possible role of neurosteroid metabolism [3], the cellular and molecular mechanisms involved in the effects of Gelsemium s. at the level of nervous system are largely unknown. To help determine these pathways, we used human neurocytes (SH-SY5Y cell line) treated in vitro with different dilutions of Gelsemium s. and evaluated their vitality and gene expression changes.
\end{abstract}

Methods: The drugs were produced by Boiron Laboratoires, Lyon (F), starting from a whole-planthydroalcoholic extract of Gelsemium s. Solutions 1C, 2C, 3C, 4C, 8C and 29C (C= centesimal dilution/dynamization prepared in 30\% ethanol/distilled water) were provided in 30-ml glass bottles, wrapped in aluminium foil and were stored in the dark at room temperature in a metal cupboard. Control solutions ("placebo") were serially diluted/dynamized 30\% ethanol/distilled water. Before each experiment, $0.05 \mathrm{ml}$ samples of Gelsemium s. and placebo were added to $5 \mathrm{ml}$ of distilled sterile and apyrogenic water in a $15 \mathrm{ml}$ Falcon polystyrene plastic tube, closed and shaken in mechanical shaker DinaA for 7.5 sec (150 strokes) to obtain the final $2 \mathrm{C}, 3 \mathrm{C}, 4 \mathrm{C}, 5 \mathrm{C}, 9 \mathrm{C}$ and $30 \mathrm{C}$ succussed dilutions, with ethanol concentration of $0.3 \%(\mathrm{v} / \mathrm{v})$ (final $0.03 \%$ in the assay system).

Human neuroblastoma cell line SHSY5Y was grown in DMEM-F12 medium (Lonza), with 10\% fetal bovine serum (FBS), penicillin (100 units $/ \mathrm{ml})$ and streptomycin $(100 \mathrm{mg} / \mathrm{ml})$. To assess cell viability and metabolism, 20,000 cells per well were seeded in 96 microplate wells in $200 \mu \mathrm{l}$ of medium. After overnight incubation, $22 \mu \mathrm{l}$ of drug or placebo were added and the plate was incubated at $37^{\circ} \mathrm{C}$ with $5 \% \mathrm{CO} 2$ in a humidified atmosphere for 72 hours. Then the viability test with reagent WST-1 (Roche) was performed for 3 hours and the absorbance was detected with multiplate reader. A total of 17 experiments, each done with six replicate microwells. To make a relative measurement of protein, the cells were lysed and a Bradford assay was done directly in the plate. The Student t-test and the sign rank test for paired data were utilized for data analysis. 
To obtain a profile of gene expression, cells were pre preconditioned with Gelsemium s./placebo dilutions for $24 \mathrm{~h}$, then RNA was isolated and analysed by microarray and RT-PCR. SHSY5Y cells were plated onto Petri dishes (day 1) and the day after the medium was replaced with the medium with $2 \%$ FBS (day 2). After $24 \mathrm{~h}$, $10 \% \mathrm{v} / \mathrm{v}$ Gelsemium s. or placebo dilutions were added to the medium (day 3) and cells were incubated for a further 24h. On day 4, cells were then harvested and the RNA extracted using the Qiagen RNAeasy Mini Kit following the manufacturer's instructions. Microarray analysis was performed on a custom $12 \mathrm{x} 135 \mathrm{k}$ human NimbleGen microarray containing 45033 genes with 3 probes per target gene. Four biological replicates were analysed for each condition. Analysis of differentially expressed genes was performed using linear modelling and empirical Bayes methods and p-values were adjusted for multiple testing with the Benjamini and Hochberg method. A Human Neurotransmitter Receptors and Regulators RT2 Profiler PCR array (Qiagen) was performed in profiling the expression of genes involved in modulating the biological processes of neurotransmitter biosynthesis, uptake, transport and signaling through neurotransmitter receptors.

Results: In viability tests, cells treated with Gelsemium s. showed slightly higher metabolic activity (3-4 \%) than those treated with placebo. Overall comparison of the data for the whole sample of placebo versus that of Gelsemium s. using the Student t-test showed a small but significant difference $(p<0.001)$. Furthermore, a non parametric approach comparing the two treatments at the same dilution yielded a significant difference under the sign test $(\mathrm{p}<0.01)$ and Wilcoxon rank test for paired data $(\mathrm{p}<0.05)$, so that the values of differences were also considered. The differences between groups having the same dilution (placebo $2 \mathrm{C}$ versus Gelsemium s. $2 \mathrm{C}$ etc.) were significant in four dilutions: $2 \mathrm{C}, 3 \mathrm{C}, 4 \mathrm{C}(\mathrm{p}<0.01), 9 \mathrm{C}(\mathrm{p}<0.02)$, while $5 \mathrm{C}$ and $30 \mathrm{C}$ yielded non-significant values. No changes due to Gelsemium s. were detected using protein assay, suggesting that the viability test revealed effects on metabolic activity instead of on cell proliferation.

In microarray analysis, transcripts expression was analyzed and genes differentially expressed by the Gelsemium s. dilutions were selected. A gene was considered to be differentially expressed if it showed an absolute value of log-ratio greater than or equal to 0.5 , an index that translates to a fold-change of 1.4 in transcript quantity. Out of a total of 45,033 transcripts, exposure to Gelsemium s. 2C promoted the selective downexpression of 49 genes ( $p$ values adj<0.05). Most of these 49 genes were downregulated also by lower Gelsemium s. dilutions (3C, 4C and 5C) and twenty even using higher dilutions (9C and 30C). Seven genes were overexpressed with Gelsemium s. $2 \mathrm{C}$ ( $p$ values adj<0.05) and 2 of these also increased their expression also in dilutions up to $9 \mathrm{C}$ and $30 \mathrm{C}$. The RT-PCR analysis is currently being done.

Conclusions: Gelsemium s. caused a small but significant positive effect on neural cell viability, both at low (2C, 3C, $4 \mathrm{C})$ and high dilutions/dynamizations (9C); the lack of activity of 5C and 30C may indicate a nonlinear dose-response, reminiscent of previous models of high-dilution pharmacology [1,4-7]. At doses which were proven non toxic in the viability and protein assays (namely $2 \mathrm{C}$ and $3 \mathrm{C}$ ), the same remedy changed in statistically significant way the expression of several genes of human neurocytes. Gene regulation by higher dilutions in this model is strongly suggested but needs statistical confirmation. The relationship between neurocyte gene regulation and the neurotropic activity of Gelsemium s., including a detailed analysis of the expression patterns involved, is under investigation.

\section{References}

[1] Magnani P, Conforti A, Zanolin E, Marzotto M, and Bellavite P, Dose-effect study of Gelsemium sempervirens in high dilutions on anxiety-related responses in mice. Psychopharmacology (Berl) 210: 533-545, 2010.

[2] Bellavite P, Conforti A, Marzotto M, Magnani P, Cristofoletti M, Olioso D, and Zanolin ME, Testing homeopathy in mouse emotional response models: pooled data analysis of two series of studies. Evid.Based.Complement Alternat.Med. 2012: 954374, 2012. 
[3] Venard C, Boujedaini N, Mensah-Nyagan AG, and Patte-Mensah C, Comparative Analysis of Gelsemine and Gelsemium sempervirens Activity on Neurosteroid Allopregnanolone Formation in the Spinal Cord and Limbic System. Evid.Based.Complement Alternat.Med doi: 10.1093/ecam/nep083: 1-10, 2011.

[4] Chirumbolo S, Brizzi M, Ortolani R, Vella A, and Bellavite P, Inhibition of CD203c membrane upregulation in human basophils by high dilutions of histamine: a controlled replication study. Inflamm.Res 58: 755-764, 2009.

[5] Witt CM, Bluth M, Albrecht H, Weisshuhn TE, Baumgartner S, and Willich SN, The in vitro evidence for an effect of high homeopathic potencies--a systematic review of the literature. Complement Ther.Med. 15: 128-138, 2007.

[6] Betti L, Trebbi G, Majewsky V, Scherr C, Shah-Rossi D, Jager T, and Baumgartner S, Use of homeopathic preparations in phytopathological models and in field trials: a critical review. Homeopathy 98: 244-266, 2009.

[7] Endler P, Thieves K, Reich C, Matthiessen P, Bonamin L, Scherr C, and Baumgartner S, Repetitions of fundamental research models for homeopathically prepared dilutions beyond 10(-23): a bibliometric study. Homeopathy. 99: 25-36, 2010.

\section{(c)) BY-NC-ND Licensed to GIRI}

Support: this work was supported by grants from Laboratoires Boiron s.r.l. (Milano, I) to Verona University and from the Ministry of University and Scientific Research.

Conflict of interest: authors declare there is no conflict of interest

Received: 01 June 2012; Revised: 08 August 2012; Published: 30 September 2012.

Correspondence author: Paolo Bellavitte, paolo.bellavite@univr.it

How to cite this article: Bellavite P, Marzotto M, Olioso D, Cristofoletti M, Brizzi M, Tononi P, Dal Prà IP, Armato U. Cellular and transcriptional responses of SH-SY5Y human neurocytes following in vitro exposure to Gelsemium sempervirens. Int J High Dilution Res [online]. 2012 [cited YYYY Month dd]; 11(40):144-146. Proceedings of the XXVI GIRI Symposium; 2012 Sep 20-22; Florence (Italy). GIRI; 2012; Available from: http://www.feg.unesp.br/ ojs/index.php/ijhdr/article/view/603/575 